\title{
VOLTAGE QUALITY ENHANCEMENT AND HARMONIC REDUCTION USING DVR
}

\author{
MANISH KUMAR SINGH \& VIVEK SAXENA
}

ABES Engineering College, Ghaziabad, Uttar Pradesh, India

\begin{abstract}
The quality of delivered power at the user terminals is one of major areas of concern in the modern power systems. It has now days become very important and essential, due to the drastic increase in the use of the sophisticated electrical devices, whose performance parameters are highly dependent and sensitive to the quality of power being delivered. Poor quality of power means nonstandard voltage, current and frequency and due to this many electrical equipment may fail in their desired operation. The major problem is linked to quality of supplied voltage which often deteriorates due to common sag in voltage amplitude and also swells in voltage. The problem of sag in voltage can be solved by use of multiple FACTS devices. Dynamic voltage restorer (DVR) is one of the extremely powerful and reliable FACTS devices for improving the profile of voltage in existing distribution systems. Different types of VSC are used in DVR to inject voltage during voltage sag by using injection transformer and different controllers. This paper provides a comprehensive survey of the researches done in the field of DVR till date. The comparative study has been done among different controllers which are used in DVR systems. This review paper also shows the performance of DVR and comparison of DVR with other FACTS devices. It has been established that DVR has got superior capability to improve the quality of voltage being delivered at the user premises as compared to other FACTS devices and also that it helps in improving the distortion in the supplied voltage.
\end{abstract}

KEYWORDS: DVR, FACTS, Injection Transformer, Voltage Sag, VSC

Received: Jun 08, 2020; Accepted: Jun 28, 2020; Published: Sep 12, 2020; Paper Id.: IJMPERDJUN20201178

\section{INTRODUCTION}

Power quality is one of the vital issues to be addressed by the electrical engineers which results due to extreme usage of loads working on solid state devices and variable loads. It has become a major problem for industrial loads keeping in mind its effect on the economic perspective. This gives rise to the necessity of monitoring of quality of power. Many of the FACTS devices were tested to improve the delivered end user power quality. One of them is DVR: it is reliable, flexible economical and has excellent voltage regulation capability. Many industries demand good voltage quality in view of a huge financial loss due to voltage sag and swell problems. Therefore it requires smooth and appropriate magnitude of voltage and also it should be continuous and uninterrupted voltage.

The poor quality of power effects all electrical equipments which are connected in power structure of a typical power system. The sophisticated equipments are more sensitive equipment and are prime cause for injection of harmonics in the distribution system. Such disturbance in power can cause the microprocessor based or programmable logic controller or microcontroller based control system to malfunction. The communication lines running parallel to power transmission lines are disturbed by electric and magnetic interference. The life of electrical equipment is also decreased due to poor power quality. False tripping of circuit breaker and flickering of 
lights are very severe problem in daily life. The considerable increment in magnitude of voltage damages the very expensive electrical and electronics devices. A lot of equipments with non-linear characteristics and whose operation requires the usage of power electronic devices inject voltage distortion and current harmonics. A momentary change in loads and switching of equipments creates transient in voltage waveform and due to this malfunction of relay and sophisticated equipments occur. At distribution stations, the voltage is not on its appropriate value that means voltage dip and voltage swell problem may occur at end users. Many industries like glass industry, semiconductor industry, manufacturing industry and financial industry are facing financial losses due to voltage dip and voltage swell. According to IEEE 1346- 1998 convention, voltage dip happens at any time instant, reduction in magnitude from 10 to 90 percent and for a short period of $1 / 2$ cycle and lasting up to one full minute. Swell in voltage is incremental in magnitude in short timing of 01 cycle to 1 minute. Many custom devices for power quality enhancement are used to minimize the dip in voltage and problems arising out of swell of voltage. The amplitude of voltage of load is the most important factor that needs to be analyzed in the power quality problems and is required to be improved for the quality of voltage before further transfer to next stage. The consumption of power is directly dependent on distribution system, so the consumers of electrical energy are affected by quality of power. The distribution station is defined as the section of power structure, which spread electrical power to the customers for use of electrical energy. Sometimes earlier power system security was employed only for generation and transmission system but in modern era, priority is also to be given to distribution system because distribution station is more disturbed by the electrical problems. The power supplied by generating power plants must be up to mark and standard so that end customers receive quality power. For transferring a good quality of power custom power devices namely UPFC, IPFC, SSSC, STATCOM, D-STATCOM etc. were used at the end of users. Generally these devices are designed and used in a coordinated manner in electrical power systems and are collectively called as FACTS Devices. Some flexible AC transmission system devices are DVR, DSTATCOM, UPQC, Active filters (AF). These devices are often utilized to subdue the causes of power quality deterioration at the end of users. Among all of these, DVR is found to be far more efficient and reliable FACTS device due to its fast action, small size and low expensive. This paper reviews and discusses comprehensively, the ability and reliability of DVR in maintaining the quality of delivered power at the level of low voltage distribution.

\section{LITERATURE REVIEW}

In [1] the author discussed the performance of DVR in medium level voltage distribution system. The voltage dip reduction in medium voltage system by using DVR has been found to be very effective and also it gave minimum effect on performance of DVR system. Its test the real time system and compares with theoretical response in case of loads having non-linear characteristics.

In [2] the effect of higher order frequencies generated by DVR system during injection of voltage has been analyzed. The frequency supplied to the load which is regulated and controlled by the use of DVR should be synchronized with the frequency of grid. So synchronization between supply frequency and frequency of the injected voltage by DVR is required. It is done by using frequency estimation method. By this estimation method performance of DVR is improved.

In [3] author focused on causes of voltage dip, voltage swell and its effects on overall system. It is challenging to contain the amplitude of voltage at appropriate value. Due to this many industries are in trouble and loss as per economic perspective. DVR is one of the very easily controllable solid state based FACTS device which are used to regulate magnitude of voltage by injection of series voltage in a distribution station. The performance of DVR is also tested on real 
time software PSCAD. It has been also discussed about how to calculate the voltage sag.

In [4] a two stepPosicast controller has been compared with the conventional PI- controller when it is used in DVR control system. Posicast controller has been found to be far more superior as compared to that with PI-controller in terms of effectiveness and simplicity. This comparative study is done on $10 \mathrm{kV}$ voltage level system and improvement in transient and steady state response has been achieved.

In [5] a powerful controller is used called as $\mathrm{P}$ plus controller ( $\mathrm{P}+$ resonant controller).It is used to control voltage profile in case of positive and negative fundamental voltage with high gain value. This controller has also been compared with PI controller.

In [6] $\mathrm{H} \infty$ controller based control technique is used in DVR which provides robust control. The performance of $\mathrm{H} \infty$ controller depends upon selecting weightage functions. Selecting different weightage functions give different output for VSI. This scheme is more reliable in condition of balanced and unbalanced dip.

In [7] authors studied the performance analysis of DVR during voltage injection by injection transformer. It is also shown that injected voltage is affected by PWM generator, capacitor and injection transformer and produces voltage harmonics. Various voltage waveforms have been obtained for various conditions such as with filter and without filter. Voltage sag at several conditions has been calculated and THD observed in resultant waveform at this different conditions.

In [8] the author focused on the use of solar energy to provide the supply for custom power devices. It demonstrates the effectiveness in performance of solar cell based dynamic voltage restorer and that saves the main supply power. Solar module based dc link is used for voltage source converters.

In [9] author discussed about Symmetrical Components Estimation which is the new strategy in which delta rule is used for reducing zero sequence and negative sequence components of power system. The advantages of this strategy are that DVR is unaffected by fluctuation in parameters. The rating of VSI has also been reduced by using the Symmetrical Components Estimation method and also low power is consumed during injection of considerable voltage.

In [10] the performance of DVR has been optimized and results have been presented to describe the ability of DVR to compensate for voltage dip caused for long duration. Experimental analysis is done on real time platform and results have been compared with the theoretical value.

In [11] it has been shown that the efficiency of DVR depends on control techniques used in switching of the inverter. Space vector PWM (SVPWM) based inverter increases the efficiency of DVR due to the ease of having digitized realization and also due to better and effective utilization of dc bus. SVPWM based inverter gives balance injected voltage during voltage sag and THD in injected voltage is reduced.

In [12] a repetitive controller has been described as a powerful controller and results have been compared with other traditional controllers. It gave better performance while compensating for voltage sag, harmonics in voltage and imbalance in three phase voltage using a DVR. Control technique used by this controller is simple and very robust. The feed forward term is used to reduce transient conditions at the time of injection of voltage and also for improving steady state conditions. Such types of control strategy response very efficiently and excellent regulation is achieved.

In [13] the author presents a powerful control technique known as hysteresis voltage control strategy on two different conditions bipolar and unipolar PWM. The parametric performance of DVR has been evaluated with different 
modes of hysteresis controller and injected voltage has been analyzed in different modes. By calculating total harmonic distortion in different hysteresis band in hysteresis controllers, various values of injected voltages was tested.

In [14] the enhanced line-interactive DVR has been described by using a novel as well as powerful detection technique for voltage sag. The analysis of this detection algorithm is done on simulation platform through the $3 \mathrm{kVA}$ interline DVR.

In [15] the detection technique used for interlines DVR, solved the problem of required dc energy source and thus dc link capacitor was self-charged. It was demonstrated and explained that two DVR are connected in each feeder with one dc link and series compensation of both feeders are achieved by individual operation of both DVR. At a time, one DVR compensated voltage dip and second one supplied electrical power to first DVR. But one of the drawbacks is that in such a combination, compensation is not possible simultaneously. It have some advantages like compensation capability is high for long duration dip in voltage, reduced and also the overall rating of the DC common link is reduced.

In [16] DVR is used as a series compensation custom power device and DSTATCOM as a shunt compensation FACTS device. D-STATCOM mitigates the sag in voltage by regulating the flow of reactive power in the system, but DVR mitigates voltage dip by injecting sufficient voltage in series by virtue of injection transformer. The compensation ability and harmonic capability of DVR is more efficient as compared to D-STATCOM in case of L-G fault. The performance of Proportional-Integral controller based DVR is found to be better than Proportional-Integral controller based D- STATCOM. Tests and result analysis of both the controllers have been done.

In [17] a low-voltage ride-through technology had been employed in a DFIG based wind turbine station and controlled by a dynamic voltage restorer (DVR). For controlling, digital filters are connected in DFIG system for expanding the positive sequence part in the imbalanced grid three phase voltage. It is advantageous for calculating the required phase shift and no reduction in amplitude of voltage output is noticed as compared to that while using the traditional low- or high-pass filters.

In [18] the control technique used for DVR reduces the stability problems in wind mill connected squirrel-cage induction generators. The controlling technique of dynamic voltage restorer is operated under unbalanced situation. Such technique is very powerful to regulate the amplitude of voltage in the case of DFIG based system. The coordinated operation of DVR and Distributed STATCOM in wind turbine system is more reliable and more efficient.

In [19] author made a comparative study between three level inverter and seven stage cascaded inverter during the operation of DVR. After comparison seven-level cascaded inverter based DVR has been found to be more efficient than three-level cascaded inverter based DVR. It has also been used with D-STATCOM and the performance has been analyzed of this custom device.

In [20] the optimization problem in interline dynamic voltage restorers (IDVRs) has been discussed. A new technique has been demonstrated by the author that enhances the performance of DVR. In this technique, two dynamic voltage restorers have been used that are interconnected via a DC link being common to both at their DC terminals. At a time one DVR is operated to for injection of voltage and the other one provides supply for the first DVR. Thus there is no requirement of storage devices. Also Interline DVR has been tested along with shunt reactance and this combination has been found to improve more percentage of voltage at the user end. A comparative study has been done between DVR and interlines DVR. It has been concluded that IDVR provides series compensation in wide range. One drawback of IDVR is 
that it consumes real power from healthy feeder in distribution system.

In [21] a novel control scheme had been proposed in which Interline DVR and two DVR are interconnected via a DC link being common to both at their DC terminals. The supply to IDVR is given by renewable sources of energy like solar and it is connected through common dc link.

In [22] author tested different causes of sag of voltage and voltage swell. One reason of voltage dip is direct on line method of starting of induction motors in industries. When induction motor starts, it draws large current and due to this voltage profile is disturbed in adjacent parallel connected sensitive loads. A solution to this problem has been proposed using DVR, which is connected in series of affected load. The control technique has been developed for coordination of various FACTS devices.

In [23] a new control technique has been developed in case of downstream fault current interruption in a feeder with the help of a dynamic voltage restorer.

In [24] a new controller has been applied in the DVR for voltage dip compensation without having the need of PLL. The fast least error digital filters have been employed to evaluate amplitude as well as phase of the injected voltage by injection transformer. This eliminates the noise component from voltage harmonics.

In [25] the use of hybrid filters in DVR has been described for filtration of harmonics. The hybrid filter has advantages of both active and passive filter and gives good response. The compensation capability of this custom device mainly depends upon controller. If response of controller is fast then response of DVR is also fast.

In [26] it has been shown that the response of DVR depends on switching technique for VSI. The authors have compared the performance of two powerful controllers namely P-I Controller and Sliding Mode Controller. It has also been explained that the performance of DVR in PMSG based wind turbine energy system enhances.

In [27] saturation condition in injection transformer during injection of injected voltage has been discussed. Due to saturation of transformer, compensating performance is reduced. The causes and effect of saturation during injection of voltage has been analyzed and the solution has been proposed to restrict the saturation of injection transformer.

In [28] the author discussed various schemes for DVR and also explained the process to minimize the rating of DVR.

In [29] a new technique Self Tuning Filter has been discussed for enhancing the performance of controller. It also compensates up to $50 \%$ voltage dip and helps in reducing the distortion in load voltage.

In [30] it has been presented that DVR is more reliable in mitigation of voltage dip with new technique of phase jump. Traditional dynamic voltage restorer is based on two stage conversion and hence size and expenses of such custom devices are a little bit higher. So by using direct $\mathrm{AC}$ to $\mathrm{AC}$ converter reduces the cost of DC link connected at the common DC terminals and the need of storage devices such as batteries and capacitor. The author explained the control strategy of direct AC-AC converter and proves that this technique is useful in enhancement of DVR and also explained the capability of AC-AC converter based DVR.

In [31] the analysis for DVR is provided for use in voltage dip reduction in the electric distribution system has been done. The dip in voltage is caused due to L-G fault in the feeder and adjacent feeder is affected by voltage reduction problem. In such type of cases it has been depicted if two DVR are connected with a common dc link and voltage sag event 
occur in one feeder, the one DVR performed the operation and the other DVR supplied to the first DVR through common dc link. Same operation has been performed when the feeder is affected by voltage dip problem.

In [32] it has been shown that Interline DVR compensation capability depends upon p.f. of the load. If p.f. of the load is low, then compensation capability increases. Therefore a shunt reactor is used which is connected parallel with the load for reducing the p.f. The Interline DVR with connected shunt reactance and based on multilevel inverter provided higher compensation as compared to IDVR without shunt reactor and single DVR with and without shunt reactor. Experimental results on IDVR have been presented on the basis of theoretical and simulation results.

In [33] three different DVR methodology of control has been analyzed and applied in three phases and four wire distribution ring system under the distorted conditions. It has been depicted that switching losses reduce and low rating of dc link is required while using two dc link based DVR. The comparative study is done among D- STATCOM, DVR and UPQC. Also different control topology in different custom devices has been discussed.

In [34] comparison between PI Controller based and fuzzy controller based custom devices has been done. Results establish that fuzzy controller is more reliable in some cases.

In [35] a new approach known as $V \cos \Phi$ control topology has been proposed and it has been applied in DVR controlling mechanism. The major advantages of this topological structure is that it controls self supported capacitor based DVR and hence there is no need of storage devices and reduces the cost of DVR. The V $\cos \Phi$ algorithm gives fast response and has less transient period.

In [36] DVR controlled by fuzzy logic controller has been incorporated in hybrid generation system of DFIG. This topology substantially improved the voltage stability, quality of power and the efficiency of the overall system. The test results have been presented for various fault conditions.

In [37] for control of DVR two stage loop circuit has been used. The outer loop is for controlling the external voltage whereas the inner loop is for control of current. The outer loop for voltage uses sequence decoupled resonant controller while the inner loop for voltage uses proportional resonant controller in the stationary frame.

In [38] cascaded $\mathrm{H}$ bridge DVR has been implemented to obtain harmonics less output voltage. The reference value for compensating voltage is adjusted along with the modulation index to obtain the desired voltage level. Also MLNT has been used to check the effectiveness of the proposed method.

\section{RESULTS AND DISCUSSIONS}

Comparative study between the various discussed methods of control for DVR has been presented in Table 1.

Table 1: Comparative Analysis of proposed Techniques in different Supply Systems

\begin{tabular}{|l|l|l|}
\hline Ref. No. & Methodology Used & \multicolumn{1}{c|}{ Results/Conclusions } \\
\hline 1 & Selective Harmonic Compensation & $\begin{array}{l}\text { Improved voltage profile with reduced voltage harmonic } \\
\text { for } 10 \mathrm{kV} \text { system. }\end{array}$ \\
\hline
\end{tabular}




\begin{tabular}{|c|c|c|}
\hline 2 & Frequency Estimation Method & $\begin{array}{l}\text { Injected voltage by DVR in system at constant } \\
\text { frequency and regulated frequency is achieved by } \\
\text { frequency estimation method }\end{array}$ \\
\hline 3 & DVR Controller using PSCAD & $\begin{array}{l}\text { DVR is more effective in series compensation device when } \\
\text { used in distribution system. }\end{array}$ \\
\hline 4 & Two Step Posicast Controller & $\begin{array}{l}\text { At medium level system, the transient response is } \\
\text { improved by the injection of voltage by injection } \\
\text { Transformer. }\end{array}$ \\
\hline 5 & $\mathrm{H} \infty$ controller & $\begin{array}{l}\mathrm{H} \infty \text { controller gives better and robust control than } \mathrm{p}+ \\
\text { controller for injectedvoltage }\end{array}$ \\
\hline 6 & $\mathrm{H} \infty$ controller & $\begin{array}{l}\text { Hळ control scheme gives better and fast response for DVR } \\
\text { during voltage sag. }\end{array}$ \\
\hline 7 & $\begin{array}{l}\text { DVR with filter controller and } \\
\text { PWM generator }\end{array}$ & $\begin{array}{l}\text { Injected voltage during voltage sag is effected by } \\
\text { PWM generator, capacitor and transformer and results in } \\
\text { voltage harmonics }\end{array}$ \\
\hline 8 & $\begin{array}{l}\text { Photovoltaic Based controller for } \\
\text { DVR }\end{array}$ & $\begin{array}{l}\text { Provides backup source for supply to voltage source } \\
\text { converter. }\end{array}$ \\
\hline 9 & $\begin{array}{l}\text { Symmetrical Components } \\
\text { Estimation }\end{array}$ & $\begin{array}{l}\text { Delta rule based Symmetrical Components Estimation } \\
\text { gives good response under the unbalanced condition. }\end{array}$ \\
\hline 10 & Cascade Inverter-Based DVR & $\begin{array}{l}\text { Less real power required during injection of voltage by } \\
\text { using cascade inverter compared to conventional inverter. }\end{array}$ \\
\hline 11 & $\begin{array}{l}\text { Space Vector PWM technique } \\
\text { based DVR }\end{array}$ & $\begin{array}{l}\text { Achieved appropriate and balanced injected voltage by } \\
\text { using space vector PWM technique. }\end{array}$ \\
\hline 12 & $\begin{array}{l}\text { Repetitive controller along with PI } \\
\text { for DVR }\end{array}$ & $\begin{array}{l}\text { Repetitive controller which has a fast transient response } \\
\text { compares to PI controller and gives zero error in steady } \\
\text { state response. }\end{array}$ \\
\hline 13 & $\begin{array}{l}\text { Hysteresis Voltage Controller for } \\
\text { DVR }\end{array}$ & $\begin{array}{l}\text { Improved quality of load voltage and reduced THD by } \\
\text { using hysteresis voltage control technique as compared to } \\
\text { PIcontroller. }\end{array}$ \\
\hline 14 & Novel Sag Detection Algorithm & $\begin{array}{l}\text { Line connected DVR along with the detection algorithm } \\
\text { compensates interrupted voltage in sensitive load. }\end{array}$ \\
\hline 15 & Interline based controller for DVR & $\begin{array}{l}\text { Interline DVR solved the problem of required dc energy } \\
\text { source and dc link capacitor is self-charged.. }\end{array}$ \\
\hline 16 & PID controller based DVR & $\begin{array}{l}\text { DVR is better series compensation device and D- } \\
\text { STATCOM is better shunt compensation device. }\end{array}$ \\
\hline
\end{tabular}




\begin{tabular}{|c|c|c|}
\hline 17 & $\begin{array}{l}\text { Fault Ride-Through Technique } \\
\text { based controller for DVR }\end{array}$ & $\begin{array}{l}\text { Performance of DVR is little bit good in DFIG system and } \\
\text { stability isconsiderable. }\end{array}$ \\
\hline 18 & $\begin{array}{l}\text { Coordinated control for DVR and } \\
\text { STATCOM }\end{array}$ & $\begin{array}{l}\text { Improved stability in wind farms under unbalanced } \\
\text { condition by using combined operation of STATCOM } \\
\text { ANDDVR. }\end{array}$ \\
\hline 19 & $\begin{array}{l}\text { Cascade Multi-level Converter } \\
\text { Based controller for DVR }\end{array}$ & $\begin{array}{l}\text { Compensation and harmonic reduction capability is higher } \\
\text { in DVR compared to the capability of D- STATCOM. }\end{array}$ \\
\hline 20 & Interline based controller for DVR & $\begin{array}{l}\text { Interline DVR have higher range of compensation } \\
\text { compared to simple DVR. }\end{array}$ \\
\hline 21 & $\begin{array}{l}\text { Photovoltaic-Based controller for } \\
\text { DVR }\end{array}$ & $\begin{array}{l}\text { Improved voltage profile in both feeders which are affected } \\
\text { from sag of voltage simultaneously with the help of } \\
\text { common dc link supply by solar cell. }\end{array}$ \\
\hline 22 & $\begin{array}{l}\text { PWM based multilevel inverter } \\
\text { controller for DVR }\end{array}$ & $\begin{array}{l}\text { Sinusoidal PWM based multilevel inverter is more efficient } \\
\text { in performance of DVR, when it is used in micro grid }\end{array}$ \\
\hline 23 & $\begin{array}{l}\text { Downstream fault current } \\
\text { detection technique }\end{array}$ & $\begin{array}{l}\text { Mitigated voltage sag in sensitive load which occurs by } \\
\text { DOL starting of } 3 \text { phase Asynchronous motor. }\end{array}$ \\
\hline 24 & $\begin{array}{l}\text { Fast Least Error Digital Filter } \\
\text { technique for DVR }\end{array}$ & $\begin{array}{l}\text { During the fault current interruption, DVR performs better } \\
\text { but it consumes real power. }\end{array}$ \\
\hline 25 & $\begin{array}{l}\text { Coordinated control of DVR using } \\
\text { Hybrid filters }\end{array}$ & $\begin{array}{l}\text { Hybrid filter have advantages of both active filter and } \\
\text { passive filter. Using this property gives better } \\
\text { filtration of harmonics }\end{array}$ \\
\hline 26 & Sliding Mode Control for DVR & $\begin{array}{l}\text { Sliding mode controller based DVR is simpler and faster } \\
\text { than PI controller based DVR when used in } \\
\text { PMSG based Wind energy system. }\end{array}$ \\
\hline 27 & $\begin{array}{l}\text { Adaptive Recursive Least Squares } \\
\text { (RLS) Method }\end{array}$ & $\begin{array}{l}\text { Controlled flux saturation is achieved in injection series } \\
\text { transformers which are used by DVR with the help of an } \\
\text { adaptive recursive least squares (RLS) method. }\end{array}$ \\
\hline 28 & $\begin{array}{l}\text { Synchronous frame theory (SRF) } \\
\text { based technique }\end{array}$ & $\begin{array}{l}\text { Rating of VSC used in DVR is reduced by using } \\
\text { Synchronous frame theory (SRF). }\end{array}$ \\
\hline 29 & $\begin{array}{l}\text { Seif Tuning filter based controller } \\
\text { for DVR }\end{array}$ & $\begin{array}{l}\text { By implementing self-tuning filter in DVR controller, } \\
\text { increases the performance of DVR as compared to } \\
\text { traditional filter. }\end{array}$ \\
\hline 30 & Phase jump technique based DVR & $\begin{array}{l}\text { AC to AC converter operated DVR which is supplied with } \\
\text { line compensated voltage sag along with phase jump and } \\
\text { there was no need of storage devices thus eliminating } \\
\text { stages of nower conversion. }\end{array}$ \\
\hline 31 & Interline based controller for DVR & $\begin{array}{l}\text { Analyzed performances of DVR for various faults in } \\
\text { medium voltage distribution system. }\end{array}$ \\
\hline
\end{tabular}




\begin{tabular}{|c|c|c|}
\hline 32 & $\begin{array}{l}\text { Shunt reactance with multilevel } \\
\text { inverter based DVR }\end{array}$ & $\begin{array}{l}\text { Interline DVR with shunt reactance gives higher range of } \\
\text { compensation and performance is better than simple DVR. }\end{array}$ \\
\hline 33 & $\begin{array}{l}\text { Multiple control strategy for } \\
\text { coordinated control of DVR with } \\
\text { FACTS devices }\end{array}$ & $\begin{array}{l}\text { Lower THD, semiconductor losses and low dc-link voltage } \\
\text { rating by applying two dc links. }\end{array}$ \\
\hline 34 & Fuzzy controller based DVR & $\begin{array}{l}\text { Fuzzy controller based DVR performance is better while it } \\
\text { is used in DSTATCOM or UPQC }\end{array}$ \\
\hline 35 & $\begin{array}{l}\text { Vcos } \Phi \text { Control Scheme of } \\
\text { Capacitor Supported DVR }\end{array}$ & $\begin{array}{l}\text { Self support capacitor connected with DVR } \\
\text { compensatescostand is moreeffectivewith regard to } \\
\text { simplicity, accuracy and quick to generate reference } \\
\text { voltages. }\end{array}$ \\
\hline 36 & $\begin{array}{l}\text { Fuzzy Logic Controller based } \\
\text { DVR }\end{array}$ & $\begin{array}{l}\text { Fuzzy logic controlled DVR improved the voltage stability } \\
\text { and quality of power substantially. }\end{array}$ \\
\hline 37 & $\begin{array}{l}\text { Sequence decoupled resonant } \\
\text { controller and proportional } \\
\text { resonant controller }\end{array}$ & $\begin{array}{l}\text { The results demonstrated that DVR was able to quickly } \\
\text { restore and stabilize the load voltage. Also it was able to } \\
\text { adapt to nonlinear loads as well. }\end{array}$ \\
\hline 38 & Cascaded $\mathrm{H}$ bridge DVR & $\begin{array}{l}\text { DVR was able to compensate against different level of } \\
\text { voltage sags caused due to variable loads. The test results } \\
\text { were obtained for } 25 \% \text { to } 5 \% \text { of voltage sags, }\end{array}$ \\
\hline
\end{tabular}

\section{CONCLUSIONS}

The paper discussed and compared the various strategies in different supply systems used by many researchers to reduce sag in voltage as well as swell in voltage and to reduce harmonics. DVR has been concluded as a very powerful device for series compensation in power system. In many cases, converter being used is a voltage source inverters consisting of static power electronics switches such as Thyristors, MOSFETs, IGBTs and GTOs. This review paper also explained different control techniques and topologies to control voltage injections by DVR and further compare with the other series or shunt FACTS power devices such as D-STATCOM, SSSC, SVC and UPQC. The control strategies discussed for DVR was analyzed for various kinds of distribution power systems such as low voltage distribution and medium voltage level distribution system. It's concluded that DVR is one of the very powerful, robust and reliable series compensating FACTS power devices among all other series compensation devices. The DVR has been found to have superb capability in improving the voltage profile and thus reducing the overall harmonic content at the end user level.

\section{REFERENCES}

1. M. J. Newman, D. G. Holmes, J. G. Nielsen and F. Blaabjerg, "A dynamic voltage restorer (DVR) with selective harmonic compensation at medium voltage level," in IEEE Transactions on Industry Applications, vol. 41, no. 6, pp. 1744-1753, Nov.Dec. 2005.doi: 10.1109/TIA.2005.858212.

2. M. Chawla, A. Rajvanshy, A. Ghosh and A. Joshi, "Distribution bus voltage control using DVR under the supply frequency variations," 2006 IEEE Power India Conference, New Delhi, 2006, pp. $6 \quad$ pp.-.doi:

10.1109/POWERI.2006.1632524.

3. ShairulWizmarWahab and Alias MohdYusof, "Voltage Sag and Mitigation Using Dynamic Voltage Restorer (DVR) System," ELEKTRIKA, 8(2), 2006, 32-37, 43976345. 
4. Y. W. Li, P. C. Loh, F. Blaabjerg and D. M. Vilathgamuwa, "Investigation and Improvement of Transient Response of DVR at Medium Voltage Level," in IEEE Transactions on Industry Applications, vol. 43, no. 5, pp. 1309-1319, Sept.-oct. 2007.doi: 10.1109/TIA.2007.904430.G. O. Young, “Synthetic structure of industrial plastics (Book style with paper title and editor),” in Plastics, 2nd ed. vol. 3, J. Peters, Ed. New York: McGraw-Hill, 1964, pp. 15-64.

5. Y. W. Li, F. Blaabjerg, D. M. Vilathgamuwa and P. C. Loh, "Design and Comparison of High Performance Stationary- Frame Controllers for DVR Implementation," in IEEE Transactions on Power Electronics, vol. 22, no. 2, pp. 602- 612, March 2007. doi: 10.1109/TPEL.2006.890002.

6. Y. W. Li, D. M. Vilathgamuwa, F. Blaabjerg and P. C. Loh, "A Robust Control Scheme for Medium-Voltage-Level DVR Implementation,"inIEEE Transactions on Industrial Electronics,vol.54,no.4,pp.2249-2261,Aug.2007.doi: 10.1109/TIE.2007.89477.

7. N. Hamzah, M. R. Muhamad and P. M. Arsad, "Investigation on the Effectiveness of Dynamic Voltage Restorer for Voltage Sag Mitigation," 2007 5th Student Conference on Research and Development, Selangor, Malaysia, 2007, pp.1-6.doi: 10.1109/SCORED.2007.4451447.

A. O. Al-Mathnani, A. Mohamed and M. A. M. Ali, "Photovoltaic Based Dynamic Voltage Restorer For Voltage Sag Mitigation," 2007 5th Student Conference on Research and Development,Selangor,Malaysia,2007,pp.1-6.doi: 10.1109/SCORED.2007.4451393.

8. M. I. Marei, E. F. El-Saadany and M. M. A. Salama, "A New Approach to Control DVR Based on Symmetrical Components Estimation," in IEEE Transactions on Power Delivery, vol. 22, no.4, pp. 2017-2024, Oct. 2007. doi: 10.1109/TPWRD.2007.905537.

9. H. Al-Hadidi, A. Gole and D. Jacobson, "Minimum power operation of cascade inverter based dynamic voltage restorer," 2008 IEEE Power and Energy Society General Meeting - Conversion and Delivery of Electrical Energy in the $21^{\text {st }}$ Century, Pittsburgh, PA, 2008, pp. 1-1. doi: 10.1109/PES.2008.4596001.

10. R. Omar and N. A. Rahim, "New control technique applied in dynamic voltage restorer for voltage sag mitigation," 2009 4th IEEE Conference on Industrial Electronics and Applications, Xi'an, 2009, pp.848-852.doi: 10.1109/ICIEA.2009.5138322.

11. P. Roncero-Sanchez, E. Acha, J. E. Ortega-Calderon, V. Feliu and A. Garcia-Cerrada, "A Versatile Control Scheme for a Dynamic Voltage Restorer for Power-Quality Improvement," in IEEE Transactions on Power Delivery, vol. 24, no. 1, pp. $277-$ 284,Jan.2009. doi: 10.1109/TPWRD.2008.2002967.

12. H. Ezoji, A. Sheikholeslami and M. Tabasi ,"Simulation of Dynamic Voltage Restorer Using Hysteresis Voltage Control" in European Journal of Scientific Research ISSN 1450-216X Vol.27 No.1 (2009), pp.152-166 @ EuroJournals Publishing, Inc. 2009.

13. B. Bae, J. Lee, J. Jeong and B. Han, "Line-Interactive Single- Phase Dynamic Voltage Restorer With Novel Sag Detection Algorithm," in IEEE Transactions on Power Delivery, vol. 25, no. 4, pp. 2702-2709, Oct.2010. doi: 10.1109/TPWRD.2010.2044194.

14. G. J. S. Dhas and T. R. D. Prakash, "A novel approach for voltage sag mitigation using facts device interline dynamic voltage restorer," 2011 3rd International Conference on Electronics ComputerTechnology,Kanyakumari,2011,pp.37- 41.doi: 10.1109/ICECTECH.2011.5941852.

15. R. Gupta, A. Ghosh and A. Joshi, "Performance Comparison of VSC-Based Shunt and Series Compensators Used for Load Voltage Control in Distribution Systems, " in IEEE Transactions on Power Delivery, vol. 26, no. 1, pp. 268-278, Jan. 2011.doi: 10.1109/TPWRD.2010.2076341.

16. O. Ibrahim, T. H. Nguyen, D. C. Lee and S. C. Kim, "A Fault Ride-Through Technique of DFIG Wind Turbine Systems Using Dynamic Voltage Restorers," in IEEE Transactions on Energy Conversion, vol. 26, no. 3, pp. 871- 882, Sept. 2011. doi: 10.1109/TEC.2011.2158102.

17. E. Leon, M. F. Farias, P. E. Battaiotto, J. A. Solsona and M. I. Valla, "Control Strategy of a DVR to Improve Stability in Wind Farms Using Squirrel-Cage Induction Generators," in IEEE Transactions on Power Systems, vol. 26, no. 3, pp.1609- 
1617,Aug.2011.doi: 10.1109/TPWRS.2010.2088141.

18. S. Mohammed, K. S. R. Rao and N. Perumal, "Cascade multi-level converter based DVR and D-STATCOM for voltage sag and swell reduction," 2011 IEEE Symposium on Computers \& Informatics, KualaLumpur, 2011, pp.390- 395.doi: 10.1109/ISCI.2011.5958947

19. M. Moradlou and H. R. Karshenas, "Design Strategy for Optimum Rating Selection of Interline DVR," in IEEE TransactionsonPowerDelivery,vol.26,no.1,pp242249,Jan.2011. doi: 10.1109/TPWRD.2010.2071403.

20. Elserougi, A. S. Abdel-Khalik, S. Ahmed and A. Massoud, "Active and reactive power management of photovoltaic-based interline dynamic voltage restorer in low voltage distribution networks," 2012 IEEE Energy Conversion Congress and Exposition (ECCE), Raleigh, NC, 2012, pp.3098-3104. doi: 10.1109/ECCE.2012.6342355.

21. Jamshidi, M. MoradiGhahderijani and S. M. Barakati, "Power quality improvement in stand-alone microgrid including fixedspeed wind farm: Role of dynamic voltage restorer," 2012 11th International Conference on Environment and Electrical Engineering, Venice, 2012, pp.206-211.doi: 10.1109/EEEIC.2012.6221574.

22. Q. Khanh, J. Lian, B. Ramachandran, S. Srivastava and D. Cartes, "Mitigating voltage sags due to DOL starting of three phase asynchronous motors using dynamic voltage restorer (DVR)," PES T\&D 2012, Orlando, FL, 2012, pp. 1-8. doi: 10.1109/TDC.2012.6281673.

23. F. BadrkhaniAjaei, S. Farhangi and R. Iravani, "Fault current interruption by the dynamic voltage restorer," 2013 IEEE Power \& Energy Society General Meeting, Vancouver, BC, 2013, pp.1-1.doi: 10.1109/PESMG.2013.6672140.

24. M. Sharanya, B. Basavaraja and M. Sasikala, "Voltage quality improvement and harmonic mitigation using custom power devices: DVR and hybrid filters," 2013 IEEE Asia Pacific Conference on Postgraduate Research in Microelectronics and Electronics (PrimeAsia), Visakhapatnam, 2013, pp.213-218.doi: 10.1109/PrimeAsia.2013.6731208.

25. M. Mahalakshmi, S. Latha and S. Ranjithpandi, "Sliding mode control for PMSG Based Dynamic Voltage Restorer," 2013 International Conference on Energy Efficient Technologies for Sustainability, Nagercoil, 2013, pp. 1320-1323.doi: 10.1109/ICEETS.2013.6533578.

26. A. Fernandes, F. F. Costa and M. A. Vitorino, "A Method for Averting Saturation From Series Transformers of Dynamic Voltage Restorers," in IEEE Transactions on Power Delivery, vol. 29,no.5, pp. 2239-2247, Oct. 2014. doi: 10.1109/TPWRD.2014.2311577

27. .P. Jayaprakash, B. Singh, D. P. Kothari, A. Chandra and Kamal-Al-Haddad, "Control of Reduced Rating Dynamic Voltage Restorer with Battery Energy Storage System," 2008 Joint International Conference on Power System Technology and IEEE Power India Conference,NewDelhi,2008,pp.1-8.doi: 10.1109/ICPST.2008.4745199.

28. S. Biricik, S. K. Khadem, S. Redif and M. Basu, "Control of the Dynamic Voltage Restorer to improve voltage quality," 2014 IEEE 5th International Symposium on Power Electronics for Distributed Generation Systems (PEDG), Galway, 2014, pp.15.doi: 10.1109/PEDG.2014.6878672.

29. S. Jothibasu and M. K. Mishra, "An Improved Direct AC-AC Converter for Voltage Sag Mitigation," in IEEE Transactions on Industrial Electronics,vol.62,no.1,pp.21-29,Jan.2015.doi: 10.1109/TIE.2014.2334668.

30. G. I. Nicolaescu, H. Andrei and S. Radulescu, "Improvement of electricity distribution services using a DVR with a constant DC voltage source instaled in MV connection substations," 2015 IEEE 15th International Conference on Environment and Electrical Engineering (EEEIC), Rome, 2015, pp.1368-1372.doi: 10.1109/EEEIC.2015.7165369.

31. M. Shahabadini and H. Iman-Eini, "Improving the Performance of a Cascaded H-Bridge-Based Interline Dynamic Voltage Restorer," in IEEE Transactions on Power Delivery, vol.31,no.3, pp.1160-1167, June2016.doi: 10.1109/TPWRD.2015.24809

32. G. A. d. A. Carlos, C. B. Jacobina and E. C. dos Santos, "Investigation on Dynamic Voltage Restorers With Two DC Links and Series Converters for Three-Phase Four-Wire Systems, " in IEEE Transactions on Industry Applications, vol. 52,no.2,pp.16081620,March-April2016.doi: 10.1109/TIA.2015.2490040.

33. M. A. A. Yahiya and M. A. R. Uzair, "Performance analysis of DVR, DSTATCOM and UPQC for improving the power quality with various control strategies, " 2016 Biennial International Conference on Power and Energy Systems: Towards Sustainable 
Energy (PESTSE), Bangalore, 2016, pp.1-4.doi: 10.1109/PESTSE.2016.751.

34. V. Rajagopal, J. Bangarraju, D. RosilaJebarani and C. Lakshmi Madhuri, "A new Vcos $\Phi$ control scheme of capacitor supported DVR for Power Quality improvement," 2016 Biennial International Conference on Power and Energy Systems: Towards Sustainable Energy (PESTSE), Bangalore, 2016, pp.1-7.doi: 10.1109/PESTSE.2016.7516537.

35. Benali, M. Khiat, T. Allaoui and M. Denaï, "Power Quality Improvement and Low Voltage Ride Through Capability in Hybrid Wind-PV Farms Grid-Connected Using Dynamic Voltage Restorer," in IEEE Access, vol. 6, pp. 68634-68648, 2018, doi:10.1109/ACCESS.2018.2878493.

36. V. T. Hung, H. Shu, L. N. Giang and N. D. The, "Double-loop control structure using proportional resonant and sequencedecoupled resonant controllers in static coordinates for dynamic voltage restorer," in Chinese Journal of Electrical Engineering, vol. 5, no. 3, pp. 10-19, Sept. 2019.

37. V. T. Hung, H. Shu, L. N. Giang and N. D. The, "Double-loop control structure using proportional resonant and sequencedecoupled resonant controllers in static coordinates for dynamic voltage restorer," in Chinese Journal of Electrical Engineering, vol. 5, no. 3, pp. 10-19, Sept. 2019. doi: 10.23919/CJEE.2019.000016. 